\title{
Perioperative Complications after Parotidectomy Using a Standardized Grading Scale Classification System
}

\author{
Natacha Terlinden ${ }^{1}$, Marc Hamoir ${ }^{1,2, * \mathbb{D}}$, Aline Van Maanen ${ }^{3} \mathbb{D}$ and Sandra Schmitz ${ }^{1,2} \mathbb{D}$ \\ 1 Department of Head and Neck Surgery, King Albert II Cancer Institute, St Luc University Hospital, \\ 1200 Brussels, Belgium; natachaterlinden@gmail.com (N.T.); sandra.schmitz@uclouvain.be (S.S.) \\ 2 Institut de Recherche Expérimentale et Clinique (IREC), Université Catholique de Louvain, \\ 1200 Brussels, Belgium \\ 3 Department of Biostatistics, King Albert II Cancer Institute, St Luc University Hospital, \\ 1200 Brussels, Belgium; aline.vanmaanen@uclouvain.be \\ * Correspondence: marc.hamoir@uclouvain.be
}

Citation: Terlinden, N.; Hamoir, M.; Van Maanen, A.; Schmitz, S.

Perioperative Complications after Parotidectomy Using a Standardized Grading Scale Classification System. Surgeries 2021, 2, 20-34. https: / / doi.org/10.3390/surgeries2010003

Academic Editor: Bernhard Meyer, Cornelis F.M. Sier

Received: 3 December 2020

Accepted: 18 January 2021

Published: 20 January 2021

Publisher's Note: MDPI stays neutral with regard to jurisdictional claims in published maps and institutional affiliations.

\begin{abstract}
Perioperative complications after parotidectomy are poorly studied and have a potential impact on hospitalization stay. The Clavien-Dindo classification of postoperative complications used in visceral surgery allows a recording of all complications, including a grading scale related to the severity of complication. The cohort analyzed for perioperative complications is composed of 436 parotidectomies classified into three types, four groups, and three classes, depending on extent of parotid resection, inclusion of additional procedures, and pathology, respectively. Using the ClavienDindo classification, complications were reported in $77 \%$ of the interventions. In 438 complications, $430(98.2 \%)$ were classified as minor (332 grade I and 98 grade II), and $8(1.8 \%)$ were classified as major (grade III). Independent variables affecting the risk of perioperative complications were duration of surgery (odds ratio $=1.007, p$-value $=0.029)$ and extent of parotidectomy (odds ratio $=4.043$, $p$-value $=0.007)$. Total $/$ subtotal parotidectomy was associated with an increased risk of grade II-III complications (odds ratio $=2.866(95 \%$ CI: 1.307-6.283), $p$-value $=0.009)$. Median hospital stay increased moderately in patients with complications. Use of Clavien-Dindo classification shows that parotidectomy is followed by a higher rate of perioperative complications than usually reported. Almost all complications are minor and have limited consequence on hospital stay.
\end{abstract}

Keywords: parotidectomy; postoperative complications; perioperative complications; salivary gland tumor; facial paralysis; hospital stay

\section{Introduction}

Parotidectomy is a surgical procedure typically performed in the surgical treatment of primary parotid gland tumors and cutaneous cancers of the head and neck with intraparotid lymph node metastases. The goal of surgery is to perform a complete tumor resection allowing local control with minimal morbidity, mainly to the facial nerve [1]. While there is an abundant literature on long term complications of parotidectomy, little is known about the prevalence and the severity of early postoperative complications occurring during the perioperative period. We hypothesized that the rate of perioperative complications after parotidectomy is underestimated because many minor complications are usually not registered. The aim of this study was to retrospectively review perioperative complications in a consecutive series of patients who underwent parotidectomy in our department, using the Clavien-Dindo classification, a standardized grading scale classification system widely used in visceral surgery [2]. 


\section{Materials and Methods}

\subsection{Patients}

The files of all patients who underwent parotidectomy in the department from January 2002 to March 2017 retrospectively reviewed. Four hundred thirty-eight surgical procedures were performed in 430 patients. Eight patients underwent two surgical procedures; three of them had a second intervention for tumor recurrence, and five patients had bilateral interventions for: Whartin's tumors in three, Mikulicz syndrome in one, and parotid lymph node metastasis from a skin carcinoma in one patient where the first parotidectomy was performed for a pleomorphic adenoma. Two patients were excluded from the analysis of complications for lack of data. Therefore, the cohort analyzed for postoperative complications is composed of 436 parotidectomies performed in 428 patients. Regarding the facial nerve function assessment specifically, eight patients with preoperative facial nerve paralysis were excluded from the analysis. Facial nerve paralysis was consecutive to previous parotidectomy performed elsewhere in three, primary carcinoma in four and previous stroke in one. The American Society of Anesthesiologists (ASA) physical status classification is a grading system based on subjective assessment of patient's overall health to determine the physical status of preoperative patients for an anesthetic risk assessment. In 1963, the American Society of Anesthesiologists (ASA) adopted a five-category physical status classification system. The ASA score, routinely used during the preoperative anesthesiology consultation, was initially based on five classes (I to V): 1. Healthy person, 2. Mild systemic disease, 3 . Severe systemic disease, 4 . Severe systemic disease that is a constant threat to life, 5 . Moribund person who is not expected to survive without the operation. Later, a sixth category was included for declared brain-dead organ donors [3]. The Body Mass Index (BMI) was recorded preoperatively according to the correlation of BMI with postoperative complications frequently reported in surgical procedures [4-7].

Parotidectomies were classified into three types, depending on extent of parotid resection. Type 1 included partial resection of the superficial parotid where the main trunk but not all branches of the facial nerve were identified; type 2 included complete resection of the superficial parotid, identifying all branches of the facial nerve; type 3 included resection of the superficial parotid and the deep lobe, partly or totally (subtotal and total parotidectomy), requiring complete release and elevation of the main trunk and branches of the facial nerve.

Surgical procedures were classified in 4 groups based on the inclusion of additional procedures to parotidectomy. Group I included parotidectomy alone, group II included parotidectomy combined with neck dissection, group III included parotidectomy combined with resection of a non-parotid tumor, and group IV included parotidectomy combined with neck dissection and resection of a non-parotid primary tumor. Finally, after definitive pathological analysis, three classes were identified. Class 1 included benign tumors and inflammatory diseases, class 2 included primary parotid malignant tumors and intraparotid lymph node metastases from non-parotid cancers, and class 3 included non-parotid primary tumors for which parotidectomy has been performed to facilitate tumor access or to achieve clear margins (Table 1).

The perioperative period was defined as the interval from the date of surgery to either the date of discharge from the hospital or 30 days after surgery, whichever occurred later. All perioperative complications, namely those reported during hospital stay and in outpatient clinic, from the day of the surgical procedure to the 30th postoperative day were recorded. A postoperative complication was defined as any deviation from the normal postoperative course not better explained by a previous medical condition, not inherent to the procedure or hospital course, and not reflective of the underlying pathophysiology of the primary diagnosis. Complication severity was retrospectively graded following the revised Clavien-Dindo classification [8]. Minor complications requiring no or minimal therapeutic intervention were classified as grades I and II, respectively. Major complications requiring surgical intervention or intensive care or resulting in death were classified as grades III, IV, and V, respectively (Table 2). The House-Brackmann grading system was 
recorded in the medical files for grading the facial nerve dysfunction [9]. During the major part of the study period, intraoperative facial nerve monitoring was only used in reinterventions and when difficulty identifying the facial nerve was anticipated. Facial nerve monitoring was routinely used from March 2015. As the distinction between seroma and sialocele was often difficult to establish retrospectively, both have been gathered under a single name.

Table 1. Classification of surgical procedures according to extent of parotidectomy, extent of overall surgical procedure, and pathology.

\begin{tabular}{ll}
\hline \multirow{3}{*}{ Extent of Parotid Resection } & $\begin{array}{l}\text { Type 1. Partial superficial parotidectomy } \\
\text { Type 2. Complete superficial parotidectomy } \\
\text { Type 3. Subtotal/Total parotidectomy }\end{array}$ \\
\hline \multirow{3}{*}{ Overall Extent of } & Group 1. Parotidectomy alone \\
Surgical Procedure & Group 2. Parotidectomy + neck dissection \\
& Group 3. Parotidectomy + resection of non-parotid tumor \\
& Group 4. Parotidectomy + neck dissection + resection of \\
non-parotid tumor
\end{tabular}

Table 2. Clavien-Dindo classification of surgical complications.

\begin{tabular}{ll}
\hline Grade & Definition \\
\hline Grade I & $\begin{array}{l}\text { Any deviation from the normal postoperative course without the need for pharmacological treatment or } \\
\text { surgical, endoscopic, and radiological interventions.Allowed therapeutic regimens are: drugs as antiemetics, } \\
\text { antipyretics, analgesics, diuretics, electrolytes, and physiotherapy.This grade also includes wound infections } \\
\text { opened at the bedside. }\end{array}$ \\
\hline Grade II & $\begin{array}{l}\text { Requiring pharmacological treatment with drugs other than those allowed for grade I complications.Blood } \\
\text { transfusions and total parenteral nutrition are also included. }\end{array}$ \\
\hline Grade III & Requiring surgical, endoscopic, or radiological intervention. \\
\hline IIIa & Intervention not under general anesthesia. \\
\hline IIIb & Intervention under general anesthesia. \\
\hline Grade IV & Life-threatening complication (including CNS complications) * requiring IC/ICU management. \\
\hline IVa & Single organ dysfunction (including dialysis). \\
\hline IVb & Multiorgan dysfunction. \\
\hline Grade V & Death of a patient. \\
\hline $\begin{array}{l}\text { Abbreviations: CNS, central nervous system; IC, intermediate care; ICU, intensive care unit. * Brain hemorrhage, ischemic stroke, and } \\
\text { subarachnoid bleeding, but excluding transient ischemic attacks. }\end{array}$
\end{tabular}

\subsection{Statistics}

Usual statistical descriptive summaries were tabulated for patients' characteristics (patient age at surgery, gender, BMI), medical history (smoking status, cardiovascular and diabetes history, ASA score, previous radiotherapy, previous parotidectomy), type of surgery (length, extent of parotidectomy, additional procedures, flap, use of monitoring, drainage), and disease information (histological type and pathological information). The prevalence of short-term complications and Clavien-Dindo grades were reported. Continuous data were summarized using descriptive statistics (mean, standard deviation, median, minimum, and maximum values). Categorical data were summarized using frequencies and percentages. Analyses were based on observed cases only. Frequency of missing data were reported, and no imputation was done. 
In order to identify potential risk factors associated with short-term complications, logistic regression analysis was used based on the proportional odds model [10]. Univariate analyses were first conducted in order to select factors to be entered into the multivariate model. Variables favoring more severe complications were analyzed by pooling together grade II and grade III complications. The rule of thumb suggest that 10 events are required for each additional predictor in a full Cox regression model. Vittinghoff et al. described more flexible rules including correlations between a predictor of choice and other covariates [11]. A backward selection was applied on other predictors in order to produce more parsimonious models. In order to rule out confounding more effectively, a liberal criterion was used during backward selection by removing only variables with $p$ values $>0.20$ [11] For each multivariate analysis, predictors required for establishing the model's face validity were included, regardless of their statistical significance [11].

Then, the final multivariate model was obtained using a backward selection among factors significantly $(p<0.20)$ associated with short-term complication. Generalized variance inflation factor (GVIF) implemented with the 'car' $R$ package was used to assess multicollinearity between predictors. Odds ratios with associated $95 \%$ Wald confidence limits were presented together with the corresponding $p$-value. For continuous explanatory variables, the odds ratio corresponded to a unit increase in the risk factors.

Due to the non-normality distribution of the duration of hospital stay distribution, the impact of perioperative complications on the duration of hospital stay was analyzed with a non-parametric test (Mann-Whitney $U$ test) comparing the number of days of hospital stay between patients with complications and patients without complication, respectively. The lengths of hospital stays were ranked according to their position when classified in ascending order. The average score was the sum of the ranks of hospital stays divided by the number of interventions. A $p$-value $<0.05$ was considered to be statistically significant.

\section{Results}

\subsection{Patient and Surgical Procedure Characteristics}

The cohort under analysis included 428 patients with a median age of 55.4 years (range: 0.3-99.9 years) who underwent 436 surgical procedures. The series was composed of 202 females (47.2\%) and 226 male patients (52.8\%). The median BMI was $25 \mathrm{~kg} / \mathrm{m}^{2}$ (range: $15.2-53.1 \mathrm{~kg} / \mathrm{m}^{2}$ ). Active smoking was reported in 143 patients $(33.4 \%)$. Preoperative ASA score was reported as ASA I in 93 patients (22.1\%), ASA II in 285 patients $(67.7 \%)$, and ASA III in 43 patients (10.2\%). In 7 patients, the ASA score was not available.

Regarding the extent of parotidectomy, type 1 was performed in $88 / 436(20.2 \%)$ procedures, type 2 in $229(52.5 \%)$ procedures, and type 3 parotidectomy in $106(24.3 \%)$ procedures. Thirteen interventions (3.0\%) were not classified for lack information.

Twenty interventions (4.6\%) were defined as re-interventions because performed in patients with local recurrence after previous surgery performed for pleomorphic adenoma in 14 patients and malignant tumor in six.

Regarding the extent of surgical procedures, group I were performed in $347(79.6 \%)$ interventions, group II in 27 interventions (6.2\%), group III in $32(7.3 \%)$, and group IV in 30 interventions $(6.9 \%)$ of surgical interventions. Overall, in addition to parotidectomy, neck dissections including at least two levels were performed in 57/436 (13.1\%) interventions. Selective neck dissections II-III were performed in 28 cases $(6.4 \%)$, II-IV in 7 (1.6\%), and II-V in $19(4.3 \%)$, when modified radical neck dissections I-V were performed in only 3 cases $(0.1 \%)$. In addition to parotidectomy, resections of a non-parotid tumors were performed in 62 cases $(14.2 \%)$, consisting in resection of primary non-parotid tumors in 59/62 $(95.2 \%)$ when these combined procedures were not directly related to parotidectomy (e.g., benign skin tumor) in the remaining three (4.8\%). At the end of the procedure, a Superficial Musculoaponeurotic System (SMAS) flap was performed in 311/436 procedures (71.3\%). Drainage of the surgical site was provided by vacuum suction drains in 314 procedures $(75.5 \%)$ and non-suction open drains in $102(24.5 \%)$ when the information was missing in $20(4.6 \%)$. 
From 2006, the duration of the surgery was precisely recorded. Accurate duration was available in 310 operations including 264 group I procedures. The median operating time for all procedures was $140 \mathrm{~min}(52-345 \mathrm{~min})$ and $130 \mathrm{~min}(52-325 \mathrm{~min})$ for group I procedures specifically.

After pathological analysis, 283/436 specimens (64.9\%) were classified as class 1 (benign and inflammatory). Among the benign tumors, two distinct tumors with different histology were diagnosed in the resected parotid specimens in two patients, resulting in a final number of 269 benign tumors. Sixteen patients (3.7\%) were operated for various inflammatory disease included sialadenitis, granulomatous reactions, ductal ectasia, and benign adenopathy. Malignant disease was diagnosed in 103/436 specimens (23.6\%) classified class 2, including 56 malignant tumors of the parotid gland (12.8\%) and 47 intraparotid malignant lymph nodes from non-parotid cancer $(10.8 \%)$, metastasis from head and neck cutaneous cancers in most of them and lymphomas. Last, 50 non-parotid tumors where parotidectomy was performed to obtain clear margins were included in class 3 . The parotid gland was reported as non-invaded in 38/50 (76\%) and invaded in 12/50 (24\%). Detailed tumor characteristics and distribution are reported in Table 3.

Table 3. Pathology characteristics. Abbreviations: $n=$ number, $\%=$ percentage.

\begin{tabular}{|c|c|c|}
\hline Pathology & $n$ & $\%$ \\
\hline Total & 438 & 100 \\
\hline Class 1: Benign & 285 & 65 \\
\hline Inflammatory Diseases & 16 & - \\
\hline Benign Tumors & 269 & - \\
\hline Pleomorphic Adenoma & 160 & - \\
\hline Whartin's tumor (cystadenolymphoma) & 82 & - \\
\hline Basal cell adenoma & 8 & - \\
\hline Oncocytoma & 7 & - \\
\hline Benign cyst & 6 & - \\
\hline Lipoma & 4 & - \\
\hline Cavernous lymphangioma & 1 & - \\
\hline Hematoma & 1 & - \\
\hline Class 2: Malignant tumors & 103 & 23.6 \\
\hline Primary Malignant Tumors & 56 & 12.8 \\
\hline Acinic cell carcinoma & 13 & - \\
\hline Mucoepidermoid carcinoma & 11 & - \\
\hline Adenoid cystic carcinoma & 7 & - \\
\hline Carcinoma ex-pleomorphic adenoma & 8 & - \\
\hline Salivary duct carcinoma & 6 & - \\
\hline Adenocarcinoma & 5 & - \\
\hline Myoepithelial carcinoma & 2 & - \\
\hline Sebaceous carcinoma & 2 & - \\
\hline Clear cell carcinoma & 1 & - \\
\hline Squamous cell carcinoma & 1 & - \\
\hline Intraparotid Lymph Node Metastases from Non-Parotid Tumors \& Lymphomas & 47 & 10.8 \\
\hline Cutaneous Squamous cell carcinoma & 16 & - \\
\hline Cutaneous Melanoma & 16 & - \\
\hline Cutaneous Merkel cell carcinoma & 6 & - \\
\hline Cutaneous Sebaceous carcinoma & 3 & - \\
\hline Lymphoma & 5 & - \\
\hline Breast lobular carcinoma & 1 & - \\
\hline
\end{tabular}


Table 3. Cont..

\begin{tabular}{ccc}
\hline Pathology & $n$ & n \\
\hline Class 3: Non primary tumors of the parotid & 50 & 11.5 \\
\hline Skin cancers & 42 & - \\
Skin cancers-Parotid not invaded & 37 & - \\
Skin cancers - Parotid invaded & 1 & - \\
Cutaneous Lymphoma (parotid not invaded) & 4 & - \\
Sarcomas (parotid invaded) & 1 & - \\
Cheek adenocarcinoma (parotid invaded) & 1 & - \\
Plexiform neurofibroma (parotid invaded) & 1 & - \\
\hline
\end{tabular}

Inflammatory Diseases, Bengin Tumors, Primary Malignant Tumors and Intraparotid Lymph Node Metastases from Non-Parotid Tumors \& Lymphomas are underscored and written in bold letters because belonging to a subdivision.

\subsection{Complications}

General complications (e.g., arterial hypertension, pressure ulcers) were reported in $18 / 436(4.1 \%)$ procedures. Local complications attributed to the anesthetic procedure were reported in $<0.1 \%(3 / 438)$ procedures as follows: pharyngeal oedema, 1 ; epistaxis, 1 , and dental dislocation, 1 . Only complications related to the surgical procedures were analyzed using the Clavien-Dindo classification. No complication was reported in 100/436 procedures $(22.9 \%)$ when one or more local complications were reported in 336 procedures (77.1\%), with an overall number of 438 reported complications (Table 4). Clavien-Dindo grade I complications were reported in 244 procedures (72.6\%), grade II in 85 interventions $(25.3 \%)$, and grade III after 7 interventions (2\%). According to the Clavien-Dindo classification, any facial nerve dysfunction regardless to the severity, observed during the first 30 postoperative days, was reported. Even patients with slight facial nerve dysfunction (grade II House-Brackmann) observed during the first postoperative days with rapid complete recovery after a few days were registered. Overall, a House-Brackmann grade II to V facial nerve dysfunction was observed after $264 / 428$ of the interventions (61.7\%). Facial nerve dysfunction was classified as Clavien-Dindo grade I in 211 procedures $(79.9 \%)$ and grade II in 53 procedures (20.1\%), respectively. In 142 interventions (32.6\%), wound healing disorders were reported. Among an overall number of 174 wound healing disorders (a few patients experienced several healing disorders), there were 83 seromas, 43 scar dehiscence, 27 local infections, 16 hematomas, and five transient salivary fistulae. Seventy seromas reported were classified as grade I $(84.3 \%)$ and 13 as grade II $(15.7 \%)$. Regarding scar dehiscences, 36 were staged as grade I $(83.7 \%)$ and seven as grade II $(16.3 \%)$. Among local infections, three were classified grade I $(11.1 \%), 23$ were grade II $(85.2 \%)$ because requiring antibiotics, and one was staged grade IIIb $(3.7 \%)$. Seven hematomas, were classified as grade I $(43.7 \%)$, two were grade II $(12.5 \%)$, and seven $(43.7 \%)$ were grade IIIb because requiring surgical intervention. All five salivary fistulae were grade I (Table 4).

Table 4. Local perioperative complications after parotidectomy according to Clavien-Dindo classification.

\begin{tabular}{cccccc}
\hline \multirow{2}{*}{ Local Complications } & \multirow{2}{*}{ Overall } & \multicolumn{4}{c}{ Grade (Clavien-Dindo) } \\
\cline { 3 - 6 } & & I & II & IIIa & IIIb \\
\hline Facial nerve impairment & 264 & 211 & 53 & - & - \\
Seroma/Sialocele & 83 & 70 & 13 & - & - \\
Dehiscence & 43 & 36 & 7 & - & - \\
Infection & 27 & 3 & 23 & - & 1 \\
Hematoma & 16 & 7 & 2 & - & 7 \\
Salivary fistula & 5 & 5 & - & - & - \\
TOTAL & 438 & 332 & 98 & - & 8 \\
\hline
\end{tabular}

Overall, in 438 reported complications, 332 were grade I (75.8\%), 98 were grade II $(22.8 \%)$, and $8(1.8 \%)$ were grade IIIb. All grade IIIb complications required surgical inter- 
vention to control hematomas and abscess. Four hundred thirty complications (98.2\%) were considered as minors (grade I and II) when only 8 complications (1.8\%) were considered as majors. No grade IV-V complications were reported.

In univariate logistic regression analysis, type 2 parotidectomy was significantly associated with a higher risk of complications compared to type 1 parotidectomy (odds ratio 1.808 (95\% CI: $1.064-3.070), p$-value $=0.028$ ). Type 3 parotidectomy was also significantly associated with a higher risk of complications compared to type 1 parotidectomy (odds ratio 4.934 (95\% CI: 2.307-10.555), $p$ value > 0.001). Duration of the procedure was significantly associated with a higher risk of complications, increasing by a factor of 1.010 per additional minute [odds ratio 1.010, $p$-value $<0.001$ ] (Table 5). In multivariate analysis, independent variables affecting significantly the risk of perioperative complications were the duration of the procedure, increasing the risk of complications by a factor of 1.007 for each additional minute (odds ratio $=1.007, p$-value $=0.029$ ) and extension of parotidectomy. Type III parotidectomy was associated with an increased risk of complications by 4 times compared to type I parotidectomy (odds ratio $=4.043, p$-value $=0.007)($ Table 6$)$.

Table 5. Univariate logistic regression with selected variables for local complications (surgical procedures: $n=436$ ). Variables with a $p$-value $<0.2$ selected for multivariate logistic analysis are in colored lines. Abbreviations: y: yes, n: no, ASA: American Society of Anesthesiologists, BMI: Body Mass Index, RT: radiotherapy, T: tumor, res.: resection, ND: neck dissection, SMAS: Superficial Musculoaponeurotic System.

\begin{tabular}{|c|c|c|}
\hline Variable & $\begin{array}{l}\text { Odds Ratio } \\
(95 \% \mathrm{CI})\end{array}$ & $p$-Value \\
\hline Age at surgery: as a continuous variable & $1.000(0.988-1.012)$ & 0.987 \\
\hline Gender: Female/Male & $1.286(0.819-2.019)$ & 0.275 \\
\hline ASA score: ASA 2 vs. 1 & $0.907(0.516-1.594)$ & 0.733 \\
\hline ASA score: ASA 3 vs. 1 & $0.797(0.342-1.855)$ & 0.599 \\
\hline BMI $\left(\mathrm{kg} / \mathrm{m}^{2}\right)$ : as a continuous variable & $0.991(0.949-1.036)$ & 0.699 \\
\hline Active smoking: $\mathrm{y} / \mathrm{n}$ & $0.733(0.462-1.163)$ & 0.187 \\
\hline Previous head \& neck RT: $y / n$ & $1.502(0.324-6.969)$ & 0.603 \\
\hline Previous parotid surgery: $y / n$ & $2.773(0.632-12.160)$ & 0.176 \\
\hline $\begin{array}{c}\text { Group } 2 \text { (Parotidectomy + ND) vs. Group } 1 \\
\text { (Parotidectomy alone) }\end{array}$ & $2.358(0.692-8.036)$ & 0.170 \\
\hline $\begin{array}{c}\text { Group } 3 \text { (Parotidectomy + other T res.) vs. } \\
\text { Group } 1\end{array}$ & $0.753(0.335-1.694)$ & 0.493 \\
\hline $\begin{array}{l}\text { Group } 4 \text { (Parotidectomy + ND + other T res.) vs. } \\
\text { Group } 1\end{array}$ & $0.688(0.303-1.562)$ & 0.371 \\
\hline $\begin{array}{c}\text { Type } 2 \text { (complete superficial) vs. Type } 1 \text { (partial } \\
\text { superficial) }\end{array}$ & $1.808(1.064-3.070)$ & 0.028 \\
\hline Type 3 (Subtotal/Total) vs. Type 1 & $4.934(2.307-10.555)$ & $<0.001$ \\
\hline Drainage: Active Suction vs. $\mathrm{n}$ & $0.832(0.486-1.423)$ & 0.502 \\
\hline Neuromonitoring: $\mathrm{y} / \mathrm{n}$ & $0.950(0.530-1.703$ & 0.864 \\
\hline SMAS flap: $\mathrm{y} / \mathrm{n}$ & $1.392(0.555-3.490)$ & 0.481 \\
\hline Surgery duration: as a continuous variable & $1.010(1.004-1.016)$ & $<0.001$ \\
\hline $\begin{array}{c}\text { Class } 2 \text { (Primary malignant parotid T) vs. Class } 1 \\
\text { (Benign parotid T) }\end{array}$ & $0.857(0.504-1.460)$ & 0.571 \\
\hline Class 3 (Non-parotid primary T) vs. Class 1 & $0.707(0.358-1.393)$ & 0.316 \\
\hline
\end{tabular}


Table 6. Multivariate logistic regression for local perioperative complications after parotidectomy (surgical procedures: $n=436$ ).

\begin{tabular}{ccc}
\hline \multicolumn{2}{c}{ Multivariate Logistic Regression Table } \\
\hline Factor & $\begin{array}{c}\text { Odds Ratio } \\
\mathbf{( 9 5 \% ~ C I )}\end{array}$ & $p$-Value \\
\hline $\begin{array}{c}\text { Surgery duration } \\
\text { as a continuous variable }\end{array}$ & $1.007(1.001-1.014)$ & 0.029 \\
\hline $\begin{array}{c}\text { Extent of parotidectomy: } \\
\text { Type 2 vs. Type 1 }\end{array}$ & $1.329(0.694-2.547)$ & 0.391 \\
\hline $\begin{array}{c}\text { Extent of parotidectomy: } \\
\text { Type 3 vs. Type 1 }\end{array}$ & $4.043(1.476-11.072)$ & 0.007 \\
\hline
\end{tabular}

Then, the analysis was focused on the risk of perioperative facial paralysis. Because facial nerve monitoring was routinely used from March 2015, neuromonitoring was used in only $76 / 436$ interventions (17.4\%). In univariate analysis, female gender was significantly associated with an increased risk of facial paralysis (odds ratio 1.515 (95\% CI: 1.022-2.247), $p$-value $=0.039$ ), group IV parotidectomy (+ neck dissection and resection of a non-parotid tumor) was associated with a lower risk of facial paralysis compared to group I parotidectomy (alone) (odds ratio 0.428 (95\% CI: 0.198-0.924), $p$-value $=0.031$ ), type 2 parotidectomy was associated with an increased risk of facial paralysis compared to type 1 parotidectomy (odds ratio 1.986 (95\% CI: 1.206-3.272), $p$-value $=0.007$ ), and type 3 parotidectomy was associated with a much higher risk of facial paralysis compared to type 1 parotidectomy (odds ratio 7.236 (95\% CI: 3.659-14.309), $p$-value < 0.001). Duration of the procedure increased the risk of facial paralysis by a factor of 1.009 for each additional minute (odds ratio 1.009 (95\% CI: 1.004-1.015), $p$-value < 0.001) (Table 7). In multivariate analysis, the duration of surgery increased the risk of facial paralysis by a factor of 1.009 for each additional minute (odds ratio $=1.009(95 \%$ CI: 1.003-1.015), $p$-value $=0.002)$, and the risk of postoperative facial paralysis was 3.7 times higher after type 3 parotidectomy than after type 1 parotidectomy (odds ratio $=3.707$ (95\% CI: 1.598-8.598), $p$-value $=0.002)($ Table 8$)$.

Similar analysis was focused on wound healing complications. In univariate analysis, none of the variables analyzed was significantly associated with a higher rate of healing disorders (Table S1). After selection of variables with a $p$-value $<0.2$ for a multivariate logistic regression analysis, higher BMI was found as independent prognostic factor with a risk increased by a factor of 1.050 for each additional BMI unit (odds ratio $=1.050(95 \% \mathrm{CI}$ : 1.001-1.101), $p$-value $=0.048)($ Table S2).

A same analysis was performed on the occurrence of postoperative seromas specifically. In univariate analysis, none of the variables analyzed was significantly associated with a higher rate of seromas (Table S3). After selection of variables with a $p$-value $<0.2$ for multivariate analysis, use of active suction drains was found as an independent prognostic factor associated with a higher risk of seroma (odds ratio $=3.797$ (95\% CI: 1.117-12.901), $p$-value $=0.033)$ (Table S4).

Next, the relation between selected variables and the severity of complications, pooling together grade II and grade III complications, was analyzed. In univariate analysis, older age was significantly associated with a little lower risk of $>$ grade I complications (odds ratio $=0.981(95 \%$ CI: 0.968-0.994), $p$-value $=0.004)$. The extent of parotidectomy was significantly associated with a higher risk of $>$ grade I complications (odds ratio $=2.963$ $(95 \%$ CI: $1.362-6.444), p$-value $=0.006)$ (Table S5). In multivariate analysis, the extent of parotidectomy was an independent prognostic factor significantly associated with a higher risk of grade II-III complications. Type 3 parotidectomy increased the risk of grade II-III complications by almost 3 times than type 1 parotidectomy (odds ratio $=2.866(95 \% \mathrm{CI}$ : $1.307-6.283), p$-value $=0.009$ ). Older age was confirmed as independent prognostic factor for a slightly lower risk of > grade I complications (odds ratio $=0.981$ (95\% CI: 0.968-0.994), $p$-value $=0.006)($ Table S6) . 
Table 7. Univariate logistic regression with selected variables for occurrence of facial paralysis as perioperative complication (surgical procedures: $n=428$ ). Variables with a $p$-value $<0.2$ selected for multivariate logistic analysis are in colored lines. Abbreviations: y: yes, n: no, ASA: American Society of Anesthesiologists, BMI: Body Mass Index, RT: radiotherapy, T: tumor, res.: resection, ND: neck dissection, SMAS: Superficial Musculoaponeurotic System.

\begin{tabular}{|c|c|c|}
\hline Variable & $\begin{array}{c}\text { Odds Ratio } \\
\text { (95\% CI) }\end{array}$ & $p$-Value \\
\hline Age et surgery: as a continuous variable & $0.998(0.987-1.008)$ & 0.656 \\
\hline Gender: Female/Male & $1.515(1.022-2.247)$ & 0.039 \\
\hline ASA score: ASA 2 vs. 1 & $0.874(0.537-1.423)$ & 0.588 \\
\hline ASA score: ASA 3 vs. 1 & $0.746(0.354-1.571)$ & 0.440 \\
\hline BMI $\left(\mathrm{kg} / \mathrm{m}^{2}\right)$ : as a continuous variable & $0.965(0.929-1.003)$ & 0.072 \\
\hline Active smoking: $\mathrm{y} / \mathrm{n}$ & $0.702(0.467-1.057)$ & 0.090 \\
\hline Previous head \& neck RT: y/n & $1.893(0.505-7.093)$ & 0.344 \\
\hline Previous parotid surgery: $\mathrm{y} / \mathrm{n}$ & $2.072(0.664-6.465)$ & 0.210 \\
\hline $\begin{array}{c}\text { Group } 2 \text { (Parotidectomy + ND) vs. Group } 1 \\
\text { (Parotidectomy alone) }\end{array}$ & $2.544(0.936-6.911)$ & 0.067 \\
\hline $\begin{array}{c}\text { Group } 3 \text { (Parotidectomy + other T res.) vs. } \\
\text { Group } 1\end{array}$ & $0.839(0.398-1.768)$ & 0.644 \\
\hline $\begin{array}{c}\text { Group } 4 \text { (Parotidectomy + ND + other T res.) vs. } \\
\text { Group } 1\end{array}$ & $0.428(0.198-0.924)$ & 0.031 \\
\hline $\begin{array}{c}\text { Type } 2 \text { (complete superficial) vs. Type } 1 \text { (partial } \\
\text { superficial) }\end{array}$ & $1.986(1.206-3.272)$ & 0.007 \\
\hline Type 3 (subtotal/total) vs. Type 1 & $7.236(3.659-14.309)$ & $<0.001$ \\
\hline Drainage: Active suction vs. $\mathrm{n}$ & $0.682(0.425-1.096)$ & 0.114 \\
\hline Neuromonitoring: $\mathrm{y} / \mathrm{n}$ & $0.803(0.484-1.331)$ & 0.394 \\
\hline SMAS flap: $y / n$ & $1.309(0.556-3.082)$ & 0.538 \\
\hline Surgery duration: as a continuous variable & 1.009 (1.004-1.015) & $<0.001$ \\
\hline $\begin{array}{c}\text { Class } 2 \text { (Primary malignant parotid T) vs. Class } 1 \\
\text { (Benign parotid T) }\end{array}$ & $1.061(0.569-1.979)$ & 0.853 \\
\hline Class 3 (Non-parotid primary T) vs. Class 1 & $0.713(0.446-1.141)$ & 0.159 \\
\hline
\end{tabular}

Table 8. Multivariate logistic regression for facial paralysis occurrence after parotidectomy (surgical procedures: $n=428)$.

\begin{tabular}{ccc}
\hline \multicolumn{2}{c}{ Multivariate Logistic Regression Table } & \\
\hline Factor & $\begin{array}{c}\text { Odds Ratio } \\
\mathbf{( 9 5 \% ~ C I )}\end{array}$ & $p$-Value \\
\hline $\begin{array}{c}\text { Surgery duration: } \\
\text { as a continuous variable }\end{array}$ & $1.009(1.003-1.015)$ & 0.002 \\
\hline $\begin{array}{c}\text { Extent of parotidectomy: } \\
\text { Type 2 vs. Type 1 }\end{array}$ & $1.110(0.601-2.050)$ & 0.738 \\
\hline $\begin{array}{c}\text { Extent of parotidectomy: } \\
\text { Type 3 vs. Type 1 }\end{array}$ & $3.707(1.598-8.598)$ & 0.002 \\
\hline
\end{tabular}

\subsection{Hospital Stay}

Finally, the correlation between occurrence of complications and duration of hospital stay was analyzed. Overall, the median hospital stay was 3 days (1-43 days, mean: 3.21 days). In surgical procedures without complication $(n=100)$, the median hospital stay was 2 days ( $2-13$ days, mean: 2.94 days) (Figure S1). In surgical procedures followed by complication(s) $(n=336)$, the median hospital stay was 3 days ( $1-43$ days, mean: 3.29 days) (Figure S2). One patient stayed in hospital for 43 days because of complications from chronic lung disease unrelated to parotid surgery. 
The median hospital stay in patients with and without postoperative transient facial paralysis was similar: 3 days (1-43 days, mean: 3.30 days) vs. 3 days ( $1-13$ days, mean: 2.88 days), respectively (Figures S3 and S4). The median hospital stay in patients with and without healing disorders was similar: 3 days (1-15 days, mean: 2.97 days) vs. 3 days (1-43 days, mean: 3.33 days), respectively (Figures S5 and S6). The median hospital stay in patients with and without seroma was 2 days (2-8 days, mean: 2.75 days) vs. 3 days (1-43 days, mean: 3.32 days), respectively (Figures S7 and S8).

A non-parametric Mann-Whitney $U$ test analysis, comparing the number of days of hospital stay between patients with and without complications, showed that hospital stay was significantly increased in patients who had perioperative complications $(p=0.0064)$. A longer hospital stay was observed in patients with postoperative facial paralysis $(p=0.0007)$ when a shorter hospital stay was observed in patients with postoperative seroma compared with patients without postoperative seroma $(p=0.0063)$ (Table 9).

Table 9. Non-parametric Mann-Whitney U test comparing lengths of hospital stays between parotidectomies with and without perioperative complications. All = overall complications $(n=436$ : analysis of all complications, wound healing disorders and seromas; $n=428$ : analysis of facial paralysis only).

\begin{tabular}{cccccc}
\hline $\begin{array}{c}\text { Perioperative Local } \\
\text { Complications }\end{array}$ & $\begin{array}{c}p \text {-Value (Wilcoxon } \\
\text { Mann-Whitney U Test) }\end{array}$ & Surgery with Complications & \multicolumn{2}{c}{ Surgery with No Complication } \\
\hline & & $\boldsymbol{n}$ & Average Score & $\boldsymbol{n}$ & Average Score \\
\hline All & 0.0064 & 336 & 226.81 & 100 & 190.59 \\
Facial paralysis only & 0.0007 & 264 & 229.29 & 164 & 190.69 \\
Wound healing (all) & 0.1102 & 142 & 205.70 & 294 & 224.680 \\
Seromas only & 0.0063 & 83 & 187.04 & 353 & 225.90 \\
\hline
\end{tabular}

\section{Discussion}

In head and neck surgery, the heterogeneity of tumors and management induces large variance in outcome data among the institutions $[12,13]$. Registration of complications in surgery is an important method used for quality improvement. Depending on the exceedingly variable definition and reporting of complications, the registered complication rate may considerably differ. Using the same definition but changing the interpretation of the definition of complications, Veen et al. shown a dramatic increase in the total number of registered complications with the implementation of a fully automated registration system and a patient-centered way of registering complications registering all adverse-events, not only related to the surgical procedure [14]. In addition, the fear that a high rate of complications could be interpreted in the medical community as evidence of poor quality of care contributes to inaccurate reporting of adverse events [13]. A consensus is clearly needed to report surgical complications using uniform definitions and registration system to assure reliable outcome data in a standardized and reproducible way, building a strong basis for comparison.

In 2004, Dindo et al. proposed a straightforward classification system to standardize surgical complications [2,8]. The Clavien-Dindo classification of postoperative complications, commonly used in general and visceral surgery, was recently adopted in head and neck surgical oncology but has not found widespread adoption, so far [13]. This classification allows a comprehensive recording of all even minor complications, including a grading scale related to the severity of complication with an easy-to-use scoring system. It allows a simple and objective comparison of the complications between different types of surgical interventions, for the same procedure over time and by surgeon within the same institution and between different institutions, respectively. The different grades of Clavien-Dindo complications are defined according to the consequences on a therapeutic level, and long-term morbidity and mortality.

The goal of our study was to analyze complications occurring during the perioperative period, assuming that these are underreported. In a retrospective review of 11,057 patients 
who underwent parotidectomy, low rates of $1.7 \%$ medical complications and $3.8 \%$ surgical complications were reported. Only wound disruptions, surgical site infections and hemorrhage/hematoma were registered as surgical complications [15]. Indeed, little is known about the true prevalence and severity of acute complications occurring during the first days following parotidectomy when long-term complications (6-24 months postoperatively) and sequalae have been extensively studied in the literature [16-18]. However, providing data about the prevalence and severity of short-term complications following parotidectomy is paramount to inform the patients properly about the risks related to surgery. Perioperative complications may have an impact on the duration of hospital stay and related costs, and, last but not least, their recognition may lead to modifications and improvements in the surgical management. Despite some limitations, we selected the Clavien-Dindo classification. Some of the problems encountered with the system include difficulties in categorizing some cases, differing morbidity may be classified similarly, and the same complication may be classified differently, depending on the treatment provided. Last, there is no differentiation between early and late postoperative complications. Consequently, comparison of series with different follow-up may become questionable. However, the simplicity, reproducibility, and logical architecture of the Clavien-Dindo system make it a convincing tool for quality assessment in surgery. Although improvements for a classification tailored to head and neck surgery should be beneficial in the near future, the importance of reporting and grading surgical complications must not be overlooked any longer. The high rate of reported complications can be explained by using a standardized grading scheme where even the most minor complications were recorded, whereas they are not usually reported with other systems. Indeed, our findings are consistent with prior reports, albeit, in other surgical subspecialties, comparing administrative datasets to chart review $[19,20]$. Heisler et al. showed that claims data accurately identifies life-threatening complications after vaginal hysterectomy when other complications are underreported [19]. This is consistent with a study addressing complications after oral cancer surgery. The authors demonstrated that $98 \%$ of all major complications were reported but many minor complications failed to report [13]. In our study, $98.2 \%$ of the complications were minor (grades I and II), while only $1.8 \%$ were considered as major (grade III).

We report a high rate of $61.7 \%$ of acute postoperative facial paralysis. In the literature, the rate of facial paralysis reported in the immediate postoperative period is extremely variable, ranging from $9.3 \%$ to $68 \%$ [21-30]. This large variability can be explained by the lack of consensus regarding the timing of facial function assessment. Indeed, even when a discrete weakness is frequently observed during the first postoperative days, spontaneous improvement occurs a few weeks later. Most of those patients are generally rated House-Brackmann grade I (normal facial function) when they are assessed a few months after surgery [31,32]. Therefore, facial function evaluation performed during the first postoperative days will be more severe on the rate of immediate paralysis. In the Clavien-Dindo classification, any deviation from the normal postoperative course must be registered. Rather than define complications a priori, all postoperative events must be recorded. Consequently, even if a slight to moderate facial nerve dysfunction following dissection of the facial nerve during parotidectomy is not an infrequent event and is expected to be reversible, we believe that it should be considered as a complication as a deviation from the normal postoperative course. In our series, a complete facial nerve recovery at 3, 6, and 12 months was observed in $86.9 \%, 93.7 \%$, and $98.1 \%$, respectively. These results are in line with those reported in the literature $[25,28,29,31,32]$. In our study, partial superficial parotidectomy is associated with a lower risk of postoperative facial paralysis. In the literature, the extent of surgical resection in the parotid gland is a wellidentified factor increasing the risk of postoperative facial paralysis $[21,25,26,29,31,33]$.

In our series, a longer duration of surgery is associated with a higher risk of postoperative complications, as it has been reported by others [19].

We are not able to demonstrate that facial nerve monitoring use of is associated with a reduction of perioperative facial paralysis. This result may be biased because during 
the major part of the study period, intraoperative facial nerve monitoring was mostly used in cases where difficulty to identifying the facial nerve was anticipated. Currently, routine use of neuromonitoring in parotid gland surgery decreases the duration of the intervention, and, accordingly, the risk of complications should be reduced. This observation should be objectively documented when an adequate number of parotidectomies under neuromonitoring will be achieved.

Other factors with a significant impact on the rate of 30-day postoperative complications were identified. An increase in BMI slightly increased the risk of healing disorders. In the whole series, the rate of seromas (and sialoceles) is higher (19.8\%) than reported by others, including sialoceles alone in partial superficial parotidectomy exclusively [34]. We show that use of active suction drainage increases the risk of developing a seroma. A recent Danish study reported that the risk of seroma and hematoma after superficial parotidectomy increased with secretion beyond $25 \mathrm{~mL} / 24 \mathrm{~h}$, questioning the use of routine drainage after superficial parotidectomy [35]. Tumor size was not analyzed as predictive factor in the absence of unambiguous data in the recent literature. In a large retrospective review of 11,057 patients who underwent parotidectomy, tumor size was not reported as predictive of postoperative complications [15]. The correlation between drainage treatment and the incidence of postoperative complication was analyzed in patients undergoing superficial parotidectomy. The authors found no significant difference between the drain/no drain groups but mentioned tumor size as a statistically significant risk factor for postoperative secretion [36].

The median hospital stay is moderately shorter in patients without complication than in patients with perioperative complications than in patients with complications. A recent study reported that partial superficial parotidectomy was associated with a shorter hospital stay and fewer complications, especially transient facial paralysis, than superficial parotidectomy [33]. Longer hospital stay is also observed in patients who had postoperative facial paralysis using non parametric analysis $(p=0.0007)$. We have shown that perioperative facial paralysis occurred more frequently in patients who had longer procedures and more extended resections of the parotid gland (Table 8), suggesting that these patients could stay hospitalized a bit longer.

Of note, patients who developed a seroma had a statistically significantly shorter hospital stay than those who did not. The occurrence of seroma could be related to a premature ablation of the drainage of the surgical site.

In our study, ASA score $>1$ is not associated with a higher risk of complications, suggesting that preexisting patient comorbidities has no influence on acute postoperative complication rates. The specific correlation of ASA scores with operating times, hospital length of stay, postoperative infection rates, overall morbidity, and mortality rates following gastrointestinal, cardiac, and genitourinary surgery has been extensively studied [37-41]. We were not able to show any correlation between ASA score and complications rates. Of note, $90 \%$ of our patients were scored ASA 1 and ASA 2. It is, however, important in similar studies to take in consideration the comorbidities to avoid biased comparison between institutions. Outcome measures need to be risk-adjusted before they are benchmarked.

Limitations to this study are first related to the retrospective nature of our analysis leading to variability in reporting complication practices meaning that many definitions were open to interpretation. This was minimized by looking at all data sources available, including recorded reports from the senior surgeons who performed all procedures, laboratory values and radiological findings. Next, a study of this magnitude is particularly laborious and time-consuming and was only possible thanks to reliance upon institutional electronic medical records. Last, although we have focused primarily on early postoperative complications, long term patient-centered clinical (and oncologic) outcomes need to be measured to assess quality of care following parotidectomy [42]. 


\section{Conclusions}

Using a standardized, scaled classification of postoperative complications, we observed that parotid gland surgery in our hands is followed by a higher 30-day postoperative complication rate than usually reported. However, almost all complications are minor and have minimal impact on the length of hospital stay. This information is important for patients and for physicians dealing with parotid gland surgery when emphasizing the favorable long-term prognosis. Despite some limitations, the Clavien-Dindo classification is a compelling tool for quality assessment in surgery.

Although improvements for a classification tailored to head and neck surgery should be beneficial, the importance of reporting and grading surgical complications must not be overlooked any longer.

Supplementary Materials: The following are available online at https:/ / www.mdpi.com/2017-201 $7 / 2 / 1 / 3 / s 1$.

Author Contributions: Conceptualization, M.H., S.S.; methodology, M.H., S.S.; validation, A.V.M.; formal analysis, N.T.; investigation, N.T.; data curation, A.V.M.; writing-original draft preparation, N.T.; writing-review and editing, M.H., S.S. All authors have read and agreed to the published version of the manuscript.

Funding: This research received no external funding.

Institutional Review Board Statement: This study was assessed by the local ethical committee and was approved after being deemed exempt from formal review. The general recommendations of discretion to personal data, as well as the Declaration of Helsinki, were followed.

Informed Consent Statement: Informed consent was not required for this retrospective study on files.

Data Availability Statement: All data respecting the anonymity of patients are available on request.

Conflicts of Interest: The authors declare no conflict of interest.

\section{References}

1. Shah, J.P.; Patel, S.G.; Singh, B. Salivary Glands. In Head and Neck Surgeryand Oncology, 4th ed.; Shah, J.P., Ed.; Elsevier: Philadelphia, PA, USA, 2012; pp. 526-569.

2. Dindo, D.; Demartines, N.; Clavien, P.A. Classification of surgical complications: A new proposal with evaluation in a cohort of 6336 patients and results of a survey. Ann. Surg. 2004, 240, 205-213. [CrossRef] [PubMed]

3. Dripps, R.D.; Lamont, A.; Eckenhoff, J.E. The Role of Anesthesia in Surgical Mortality. JAMA 1961, 178, 261-266. [CrossRef] [PubMed]

4. Kim, B.D.; Lim, S.; Wood, J.; Samant, S.; Halen, J.P.V.; Kim, J.Y.S. Predictors of Adverse Events After Parotidectomy. Ann. Otol. Rhinol. Laryngol. 2015, 124, 35-44. [CrossRef] [PubMed]

5. Gierth, M.; Zeman, F.; Denzinger, S.; Vetterlein, M.W.; Fisch, M.; Bastian, P.J.; Syring, I.; Ellinger, J.; Müller, S.C.; Herrmann, E.; et al. Influence of Body Mass Index on Clinical Outcome Parameters, Complication Rate and Survival after Radical Cystectomy: Evidence from a Prospective European Multicentre Study. Urol. Int. 2018, 101, 16-24. [CrossRef] [PubMed]

6. Bono, O.J.; Poorman, G.W.; Foster, N.; Jalai, C.M.; Horn, S.R.; Oren, J.; Soroceanu, A.; Ramachandran, S.; Purvis, T.E.; Jain, D.; et al. Body mass index predicts risk of complications in lumbar spine surgery based on surgical invasiveness. Spine J. 2018, 18, 1204-1210. [CrossRef] [PubMed]

7. Sems, S.A.; Johnson, M.; Cole, P.A.; Byrd, C.T.; Templeman, D.C.; Minnesota Orthopaedic Trauma Group. Elevated Body Mass Index Increases Early Complications of Surgical Treatment of Pelvic Ring Injuries. J. Orthop. Trauma 2010, 24, 309-314. [CrossRef]

8. Clavien, P.-A.; Barkun, J.; De Oliveira, M.L.; Vauthey, J.N.; Dindo, D.; Schulick, R.D.; De Santibañes, E.; Pekolj, J.; Slankamenac, K.; Bassi, C.; et al. The Clavien-Dindo Classification of Surgical Complications. Ann. Surg. 2009, 250, 187-196. [CrossRef]

9. House, J.W.; Brackmann, D.E. Facial Nerve Grading System. Otolaryngol. Neck Surg. 1985, 93, 146-147. [CrossRef]

10. Agresti, A. Categorical Data Analysis, 2nd ed.; John Wiley \& Sons: New York, NY, USA, 2002.

11. Vittinghoff, E.; Glidden, D.V.; Shiboski, S.C.; McCulloch, C.E. Regression Methods in Biostatistics; Springer: New York, NY, USA, 2012; pp. 395-429.

12. Jalisi, S.; Bearelly, S.; Abdillahi, A.; Truong, M.T. Outcomes in head and neck oncologic surgery at academic medical centers in the united states. Laryngoscope 2013, 123, 689-698. [CrossRef]

13. Awad, M.I.; Shuman, A.G.; Montero, P.H.; Palmer, F.L.; Shah, J.P.; Patel, S.G. Accuracy of administrative and clinical registry data in reporting postoperative complications after surgery for oral cavity squamous cell carcinoma. Head Neck 2014, 37, 851-861. [CrossRef] 
14. Veen, E.J.; Janssen-Heijnen, M.L.G.; Leenen, L.P.H.; Roukema, J.A. The Registration of Complications in Surgery: A Learning Curve. World J. Surg. 2005, 29, 402-409. [CrossRef]

15. Bovenzi, C.; Ciolek, P.; Crippen, M.; Curry, J.M.; Krein, H.; Heffelfinger, R. Reconstructive trends and complications following parotidectomy: Incidence and predictors in 11,057 cases. J. Otolaryngol. Head Neck Surg. 2019, 48, 1-8. [CrossRef] [PubMed]

16. Wolber, P.; Volk, G.; Horstmann, L.; Finkensieper, M.; Shabli, S.; Wittekindt, C.; Klussmann, J.; Guntinas-Lichius, O.; Beutner, D.; Grosheva, M. Patient's perspective on long-term complications after superficial parotidectomy for benign lesions: Prospective analysis of a 2-year follow-up. Clin. Otolaryngol. 2018, 43, 1073-1079. [CrossRef]

17. Kaya, B.V.; Kilic, C.; Özlügedik, S.; Tuncel, Ü.; Cömert, E. Long-term effects of parotidectomy. Eur. Arch. Oto-Rhino-Laryngol. 2016, 273, 4579-4583. [CrossRef] [PubMed]

18. Fang, Q.-G.; Shi, S.; Zhang, X.; Li, M.; Liu, F.-Y.; Sun, C.-F. Long term quality of life in pediatric patients surviving parotid tumors. Int. J. Pediatr. Otorhinolaryngol. 2014, 78, 235-237. [CrossRef] [PubMed]

19. Heisler, C.A.; Melton, L.J.; Weaver, A.L.; Gebhart, J.B. Determining Perioperative Complications Associated with Vaginal Hysterectomy: Code Classification Versus Chart Review. J. Am. Coll. Surg. 2009, 209, 119-122. [CrossRef]

20. Romano, P.S.; Chan, B.K.; Schembri, M.E.; Rainwater, J.A. Can Administrative Data Be Used to Compare Postoperative Complication Rates Across Hospitals? Med. Care 2002, 40, 856-867. [CrossRef]

21. Dulguerov, P.; Marchal, F.; Lehmann, W. Postparotidectomy facial nerve paralysis: Possible etiologic factors and results with routine facial nerve monitoring. Laryngoscope 1999, 109, 754-762. [CrossRef]

22. Bova, R.; Saylor, A.; Coman, W.B. Parotidectomy: Review of treatment and outcomes. ANZ J. Surg. 2004, 74, 563-568. [CrossRef]

23. Bron, L.P.; O’Brien, C.J. Facial Nerve Function After Parotidectomy. Arch. Otolaryngol. Head Neck Surg. 1997, 123, 1091-1096. [CrossRef]

24. Stodulski, D.; Skorek, A.; Mikaszewski, B.; Wiśniewski, P.; Stankiewicz, C. Facial nerve grading after parotidectomy. Eur. Arch. Oto-Rhino-Laryngol. 2015, 272, 2445-2450. [CrossRef]

25. Koch, M.; Zenk, J.; Iro, H. Long-term results of morbidity after parotid gland surgery in benign disease. Laryngoscope 2010, 120, 724-730. [CrossRef]

26. Roh, J.-L.; Park, C.I. A prospective, randomized trial for use of prednisolone in patients with facial nerve paralysis after parotidectomy. Am. J. Surg. 2008, 196, 746-750. [CrossRef]

27. Gaillard, C.; Périé, S.; Susini, B.; Guily, J.L.S. Facial Nerve Dysfunction After Parotidectomy: The Role of Local Factors. Laryngoscope 2005, 115, 287-291. [CrossRef]

28. Mehle, M.E.; Kraus, D.H.; Wood, B.G.; Benninger, M.S.; Eliachar, I.; Levine, H.L.; Tucker, H.M.; Lavertu, P. Facial nerve morbidity following parotid surgery for benign disease: The cleveland clinic foundation experience. Laryngoscope 1993, 103, 386-388. [CrossRef]

29. Guntinas-Lichius, O.; Klussmann, J.P.; Wittekindt, C.; Stennert, E. Parotidectomy for Benign Parotid Disease at a University Teaching Hospital: Outcome of 963 Operations. Laryngoscope 2006, 116, 534-540. [CrossRef]

30. Marchese-Ragona, R.; De Filippis, C.; Marioni, G.; Staffieri, A. Treatment of complications of parotid gland surgery. Acta Otorhinolaryngol. Ital. 2005, 25, 174-178.

31. Upton, D.C.; McNamar, J.P.; Connor, N.P.; Harari, P.M.; Hartig, G.K. Parotidectomy: Ten-Year Review of 237 Cases at a Single Institution. Otolaryngol. Neck Surg. 2007, 136, 788-792. [CrossRef]

32. Bittar, R.F.; Ferraro, H.P.; Ribas, M.H.; Lehn, C.N. Facial paralysis after superficial parotidectomy: Analysis of possible predictors of this complication. Braz. J. Otorhinolaryngol. 2016, 82, 447-451. [CrossRef]

33. Mlees, M.A.; Elbarbary, A.H. Superficial or partial superficial parotidectomy for the treatment of primary benign parotid tumors. J. Surg. Oncol. 2020, 122, 1315-1322. [CrossRef]

34. Lee, Y.C.; Park, G.C.; Lee, J.-W.; Eun, Y.; Kim, S.W. Prevalence and risk factors of sialocele formation after partial superficial parotidectomy: A multi-institutional analysis of 357 consecutive patients. Head Neck 2016, 38, E941-E944. [CrossRef] [PubMed]

35. Nielsen, C.F.; Riis, C.B.S.; Christensen, A.L.B.; Mirz, F.; Reinholdt, K.B.; Ovesen, T.; Fjaeldstad, A.W. Superficial Parotidectomy: Impact of Postoperative Drainage. Ear. Nose Throat J. 2020. [CrossRef] [PubMed]

36. Andrew, J.; Coniglio, M.D.; Allison, M.; Deal, M.S.; Trevor, G.; Hackman, M.D. Outcomes of drainless outpatient parotidectomy. Head Neck 2019, 41, 2154-2158. [CrossRef]

37. Ridgeway, S.; Wilson, J.; Charlet, A.; Kafatos, G.; Pearson, A.; Coello, R. Infection of the surgical site after arthroplasty of the hip. J. Bone Jt. Surg. Br. Vol. 2005, 87, 844-850. [CrossRef]

38. Tang, R.; Chen, H.H.; Wang, Y.L.; Changchien, C.R.; Chen, J.-S.; Hsu, K.-C.; Chiang, J.-M.; Wang, J.-Y. Risk Factors For Surgical Site Infection After Elective Resection of the Colon and Rectum: A Single-Center Prospective Study of 2809 Consecutive Patients. Ann. Surg. 2001, 234, 181-189. [CrossRef]

39. Sauvanet, A.; Mariette, C.; Thomas, P.; Lozac'H, P.; Segol, P.; Tiret, E.; Delpero, J.-R.; Collet, D.; Leborgne, J.; Pradère, B.; et al. Mortality and Morbidity after Resection for Adenocarcinoma of the Gastroesophageal Junction: Predictive Factors. J. Am. Coll. Surg. 2005, 201, 253-262. [CrossRef]

40. Prause, G.; Offner, A.; Ratzenhofer-Komenda, B.; Vicenzi, M.; Smolle, J.; Smolle-Jüttner, F. Comparison of two preoperative indices to predict perioperative mortality in non-cardiac thoracic surgery. Eur. J. Cardio Thorac. Surg. 1997, 11, 670-675. [CrossRef] 
41. Carey, M.S.; Victory, R.; Stitt, L.; Tsang, N. Factors That Influence Length of Stay for In-Patient Gynaecology Surgery: Is The Case Mix Group (CMG) or Type of Procedure More Important? J. Obstet. Gynaecol. Can. 2006, 28, 149-155. [CrossRef]

42. Porter, M.E. What Is Value in Health Care? N. Engl. J. Med. 2010, 363, 2477-2481. [CrossRef] 